\title{
Revision Article
}

\section{A review of the effect of compassion on mental health: emotion regulation as a possible mechanism of action}

\author{
Dr. Andrés S. Lombas \\ Departamento de Psicología y Sociología, Universidad de Zaragoza \\ Autor correspondencia: slombas@unizar.es
}

Recibido: 25/10/2018; Aceptado: 05/12/2018; Publicado: 30/01/2019

\begin{abstract}
Resumen: Este artículo proporciona una revisión del actual estado de la investigación en compasión. Primero, se aborda el constructo de compasión desde una perspectiva Budista. Segundo, el artículo revisa la literatura empírica sobre la relación de la auto-compassión con la salud mental, incluyendo hallazgos de estudios correlacionales así como de estudios de intervenciones. Tercero, se diferencia conceptualmente entre la compasión y la empatía, proporcionando evidencia empírica que apoya esta distinción. Cuarto, se discute la idea de que un posible mecanismo de acción de la auto-compasión en la salud mental puede ser por medio de mejoras en la regulación emocional. Finalmente, se concluye que la investigación en compasión es todavía emergente y se sugieren líneas de futuras investigaciones.
\end{abstract}

Palabras Clave: Compasión; Empatía, Regulación Emocional; Salud Mental.

Abstract: This article provides a review of the current state of research on compassion. First, the construct of compassion is addressed from a Buddhist perspective. Second, this article reviews the empirical literature on the relation of self-compassion to mental health, including findings from correlational studies as well as intervention studies. Third, compassion and empathy are conceptually differentiated, providing empirical evidence that supports this distinction. Fourth, the idea is discussed that a possible mechanism of action for self-compassion on mental health may be through improvements on emotion regulation. Finally, it is concluded that research on compassion is still emergent and directions for future research are suggested.

Key words: Compassion; Empathy; Emotion Regulation; Mental Health.

\section{Definitions and components of the construct of compassion}

After an explosion of research into the benefits of mindfulness in mental health and well-being, now interest is increasingly focusing attention on researching the benefits of compassion. The construct of compassion has been defined in several ways, depending on the perspective from which this construct has been addressed: evolutionist, moral, emotional, religious.... [1]. To date, researchers have not yet reached a consensus about how to define it. However, much research has investigated compassion from a Buddhist perspective. From this perspective, His Holiness the Dalai Lama [2] described compassion as a state of mind in which one desires others to be free from suffering. In a similar vein, compassion has been conceptualized as the feeling that arises in witnessing another's suffering and that motivates a subsequent desire to help [1]. Etymologically, the term compassion is derived from the Latin origins "com" (with/together) and "pati" (to suffer).

When compassion is directed to oneself, then the term self-compassion is used. More specifically, self-compassion involves being caring and compassionate toward oneself during times of difficulty $[3,4]$. Neff $[5,6]$ has postulated that self-compassion consists of three components: 1$)$ extending kindness and understanding to oneself rather than harsh self-criticism and judgment (i.e., selfkindness versus self-judgment); 2) seeing one's experiences as part of the larger human experience rather than as separating and isolating (i.e., common humanity versus isolation); and 3) holding one's 
painful thoughts and feelings in balanced awareness rather than over-identifying with them (i.e., mindfulness versus overidentification).

\section{Four immeasurables}

According to Visuddhimagga (a Pali word which in English means "The Path of Purification"; [7]), the most important treatise on Theravada Buddhism that summarizes and systematizes the theoretical and practical teachings of Gautama Buddha, there are four sublime states (Brahma Viharas in Sanskrit; also known as noble and divine abodes or "immeasurables") that can be cultivated. The first one is Loving-kindness (metta in Pali), which is the wish that all sentient beings, without any exception, be happy. The second one is Compassion (karuna in Pali), which is the wish for all sentient beings to be free from suffering. The third one is Appreciative Joy (mudita in Pali), which is the attitude of rejoicing in the happiness and virtues of all sentient beings. The fourth one, and the last one, is Equanimity (uppekkha in Pali), which is the attitude of regarding all sentient beings as equals, irrespective of their present relationship to oneself.

Compassion and loving-kindness are related constructs. In fact, Germer [8] considers compassion as a subtype of loving-kindness; when there is suffering, then we talk about compassion. When there is not, then we talk about loving-kindness. In other words, compassion is loving-kindness directed towards suffering.

According to Buddhist tradition, compassion meditation consists of a series of steps in which the meditator wishes others: (1) to be free from enmity; (2) to be free from mental suffering; (3) to be free from physical suffering; and (4) to take care of him/herself happily [9]. It is well worth noting that wishes can also be directed to oneself.

In loving-kindness meditation the meditator wishes happiness, but the person to whom the wishes are addressed changes in each step. Specifically, the meditator wishes happiness: (1) to $\mathrm{him} /$ herself; (2) to a good friend; (3) to a neutral person (i.e., a person that does not elicit either positive or negative feelings); (4) to a difficult person (i.e., a person that evokes negative feelings); (5) simultaneously, to him/herself, the good friend, the neutral person, and the difficult person, distributing equally the wishes among them; and (6) to the entire universe [9].

\section{Self-compassion and mental health}

Theoretically, self-compassion is an important factor of mental health, because in selfcompassionate people the psychological suffering, that eventually one experiences in life, presumably are not exaggerated and maintained through harsh self-criticism [10], feelings of loneliness [11] and over-identification with thoughts and emotions [12]. There is a growing body of evidence supporting this idea. For example, Neff [5] found that self-compassion had a negative association with anxiety and depression, and a positive association with life satisfaction. The negative associations found between self-compassion with anxiety and depression also remained after controlling, separately, for self-criticism and self-esteem. Similarly, the positive association found between self-compassion and life satisfaction also remained after controlling for self-criticism. Other authors [13] reported a negative association between self-compassion and stress.

A meta-analysis [14] reviewed the research on the associations of self-compassion with anxiety, depression and stress, and estimated their average effect sizes. Results revealed large effect sizes for all the associations ( $r=-.58$ for anxiety and depression and $r=-.61$ for stress) and did not show evidence of significant publication bias, demonstrating that higher levels of compassion were associated with lower levels of mental health symptoms. Moreover, differential effects were not found among study populations, age and gender.

When the capability of self-compassion to predict depressive and anxious symptomatology, as well as quality of life, has been compared with respect to mindfulness, results have shown that selfcompassion is ten times bigger than that of mindfulness; whereas self-compassion accounted for between $10 \%$ and $27 \%$ of the mentioned variables, mindfulness only accounted for between $1 \%$ and $3 \%[15]$. 
Further evidence on the positive impact that self-compassion has on depression and anxiety has been obtained through interviews with patients diagnosed with either depression or anxiety, after being introduced to the concept of self-compassion. Thus, the majority of the patients reported that this concept had meaning for them and that it was useful for them in terms of trying to overcome anxiety and depression. At the same time, they expressed that they found it difficult to develop and maintain a self-compassionate stance. In fact, they felt that their disorder made them experience the exact opposite of self-compassion [16].

Supporting evidence of self-compassion as an important factor in mental health is not limited to its relation with ill-being, but also with well-being. Thus, research has also found that self-compassion had a positive correlation with self-esteem, social connectedness, emotional intelligence [5], happiness and positive affect [17].

Further evidence comes from a meta-analysis [18] that examined the associations between selfcompassion and different forms of well-being. Results showed that the magnitudes of these associations were different from each other. The strongest effect size was found between selfcompassion and psychological well-being $(r=.62)$, followed by negative affect $(r=-.47)$ and cognitive well-being $(r=.47)$. The weakest effect size was found between self-compassion and positive affective well-being $(r=.39)$. Therefore, the magnitude of the associations ranged between medium to large effect sizes. The meta-analysis did not find evidence of significant publication bias.

\section{Effects of compassion interventions}

Most psychological interventions that are based on Buddhist meditations add loving-kindness and compassion practices together. These meditations have been included in programs aimed at improving mental health and wellbeing. One program is Mindful Self-Compassion (MSC), which has been developed by Neff and Germer [19]. A randomized controlled trial of this program has shown that the MSC program increased self-compassion and mindfulness of experimental participants as compared with waitlist controls, of which effect sizes were large and medium respectively. The MSC program also increased life satisfaction and reduced anxiety, depression, stress, and avoidance. Positive results were also found in another randomized controlled trial where the MSC program was applied to patients with Type 1 and Type 2 diabetes. Concretely, intervention increased selfcompassion and reduced depression, diabetes distress and glycemic levels, respective to a wait-list control group.

The MSC program has been adapted for adolescents [20]. This adaptation has been named Making Friends with Yourself. An evaluation of this program, through a crossover randomized controlled trial, has shown that, after the intervention, the experimental group had greater mindfulness and self-compassion, and less anxiety, depression, perceived stress and negative affect, compared to the waitlist control.

Apart from MSC, there are other compassion-based programs, such as Cultivating Emotional Balance [21], Compassion Cultivation Program [22], Being with Dying Professional Training Program [23], Compassion-Focused Therapy [24], Attachment-Based Compassion Therapy [25], The Resource Model [26] and the Cognitively-Based Compassion Training [27].

\section{Compassion and empathy}

Empathy is often used as a synonym with compassion [28]. These terms have been conceptually differentiated [29]. Empathy refers to the ability to resonate with others' emotional states (which can be positive or negative). Thus, we can experience happiness when others enjoy life, and we can experience suffering when others are in pain. On the contrary, compassion is conceived as the desire that others be free from suffering.

Although empathy and compassion have been conceptualized as different constructs, this does not mean that they are unrelated from each other. In fact, Vicente [30] has proposed that the appearance of compassion requires the initial surge of empathetic feelings. However, to this author's knowledge, all the experiments that have been performed to date on this subject have sought to investigate the influence of compassion training on empathy, and not the other way around. Thus, 
for example, in an experiment carried out by Antoine Lutz and collaborators [31], a voice of a distressed person was presented to two groups of participants: expert participants, with thousands of hours of practice in compassion meditation, and novice participants in this type of meditation. Experts had stronger activation in somatosensory and insular cortices than novices to negative emotional voices during compassion meditation. Likewise, the strength of activation in insula was also associated, for both groups, with the degree to which participants perceived that they had successfully entered into the meditative state. These findings suggest that compassion meditation can enhance empathic responses to social stimuli.

Olga Klimecki and Tania Singer [32,33] have also studied the effects of compassion on empathy in three experiments. In the first experiment [32], some participants received training in compassion and others in a memory-enhancing technique. All participants viewed, before and after the training, short documentary video clips depicting people in pain or in everyday life situations. Participants' brain responses were measured while they were watching the videos. In addition, after each video, participants were asked about their positive and negative feelings, as well as their levels of empathy. Even though compassion training did not have an effect on negative emotion, compared with a memory control group, it augmented positive emotion (in both video clips) and empathy (in video clips of everyday life situations). On the neural level, compassion training activated the medial orbitofrontal cortex, the putamen, the pallidum, and the ventral tegmental area; brain regions that have been associated with positive affect and affiliation in previous studies.

The second experiment [33] performed by Olga Klimecki and Tania Singer was similar to the first one, except that participants that received training in compassion also received training in empathy. The sequence of training followed this order: first empathy training and later compassion training. Results showed that, whereas empathy training increased empathic responses and negative affect (in both video clips) in response to others' distress, compassion training decreased negative affect back to baseline levels and increased positive affect. Neuroimaging data revealed distinct patterns of brain activity after compassion and empathy training. While empathy training involved the activation of anterior insula and anterior midcingulate cortex (brain regions previously associated with empathy for pain), brain regions activated during compassion training were ventral striatum, pregenual anterior cingulate cortex and medial orbitofrontal cortex (brain networks related to positive affect, affiliation and reward).

Taking these two experiments together, authors concluded that these results provide evidence for functional neural plasticity induced by both empathy and compassion training, underlining the important distinction between empathy and compassion, both on a psychological and neurological level. On a psychological level, empathy training does not only seem to induce painful and distressing experiences when exposed to others' suffering, but it also seems to increase the susceptibility to feel negative affect in response to everyday life situations. On the contrary, compassion training seems to reverse these effects by returning negative affect to baseline levels and augmenting positive affect, which suggests that compassion may help to foster resilience. Importantly, this is not achieved through desensitizing from others' suffering, since compassion training does not reduce empathy. Acknowledging others' suffering rather than ignoring it may be a crucial factor for the development of prosocial motivation and helping behavior.

In line with this, in a third experiment, Olga Klimecki and Tania Singer [34] have shown that compassion training, but not memory training, increased helping behavior through the use of a computer game, developed to measure prosocial behavior. Oppositely to what it is found after compassion training, some studies have shown that experience of empathy may lead to withdrawal tendencies $[35,36]$.

During a study carried out by Tania Singer and her colleagues, Matthieu Ricard, a Buddhist monk and researcher that participated as an expert on compassion meditation, realized that empathic resonance is a very aversive experience and, therefore, may be a risk factor for emotional burnout. Empathic resonance refers to a reaction characterized by emotional numbness and detachment from others [37]. On the contrary, compassion could be a protective factor against burnout. Specifically, Matthieu Ricard's words [38] were the following: 
So when I was immersing myself in empathic resonance, I visualized the suffering of these orphan children as vividly as possible. The empathic sharing of their pain very quickly became intolerable to me and I felt emotionally exhausted, very similar to being burned out. After nearly an hour of empathic resonance, I was given the choice to engage in compassion or to finish scanning. Without the slightest hesitation, I agreed to continue scanning with compassion meditation, because I felt so drained after the empathic resonance. Subsequently engaging in compassion meditation completely altered my mental landscape. Although the images of the suffering children were still as vivid as before, they no longer induced distress. Instead, I felt natural and boundless love for these children and the courage to approach and console them. In addition, the distance between the children and myself had completely disappeared. This was when we realized the immense potential of compassion as an antidote to empathic distress and burnout. (p. 279).

Based on this experience, Klimecki, Ricard and Singer [38] have suggested that self-compassion may be an important skill to teach caregivers to prevent burnout. They have argued that if caregivers respond to their patient's suffering with compassion, they will empathize with the suffering, but not identify with it, and thus will be able to contain their own negative feelings. In contrast, if caregivers identify with the suffering of their patient, their identification could lead them to feel distressed, which over the longer term could lead to burnout.

In accordance with this suggestion, there is evidence that a yoga and compassion meditation program reduces stress in familial caregivers of Alzheimer's disease patients [39]. More importantly, a longitudinal study [40], that examined the culture's influence on employees in a long-term care setting, found that those employees who did not work in units characterized by compassionate love showed poorer performance and engagement with their work. In addition, their work satisfaction was lower, they felt more exhausted, and their absenteeism was higher.

\section{Self-compassion and emotional regulation}

Emotion regulation refers to the ways in which individuals attend to and appraise their emotions as well as the ways they modulate the intensity and duration of emotional states [41, 42]. Since selfcompassion involves the transformation of negative feelings (i.e., feeling bad about one's inadequacies or failures) into positive feelings (i.e., feeling kindness and understanding toward oneself), self-compassion can be viewed as an emotional regulation strategy $[5,6]$. On the other hand, it is well recognized that emotion regulation is a transdiagnostic factor that underlies a wide range of psychological disorders [43, 44]. Bearing all this in mind, Finlay-Jones, Rees and Kane [45] have proposed emotion regulation as a possible mechanism of action for self-compassion on mental health. Concretely, they hypothesize that the ability of self-compassion to promote mental health may be due to improvements in emotion regulation. Supporting this idea, they have found evidence that the effect of self-compassion on stress is mediated by emotional regulation.

Klimecki and Singer [33] have suggested that compassion is an emotion regulation strategy different from other emotion regulation strategies, such as suppression or reappraisal, which involve an active down-regulation of negative affect [46]. In response to the presence of suffering, the generation of compassion allows strengthening of positive affect, while not ignoring or changing the negative reality. Thus, compassion does not lead to the denial of suffering, but it enables people to experience positive emotions, in spite of another person's difficulty. Compassion does not lead to the avoidance of painful or distressing feelings either. On the contrary, these feelings are recognized and held in awareness with kindness, understanding, and a sense of shared humanity. To sum up, the generation of compassion does not only give rise to positive consequences to others by obtaining the necessary help, but it also is beneficial for oneself by providing a potentially powerful coping strategy.

\section{Future studies on compassion}

Although there is a growing body of evidence suggesting that compassion-based interventions have promising potential for improving mental health and well-being, research on this topic is still in its infancy and, therefore, more research is needed. Future research should confirm previous 
findings and address new issues that to date have not been explored. For example, although theoretically compassion is supposed to prevent burnout [38], little research has empirically examined this assertion. Likewise, despite there being existing evidence that compassion may promote empathy $[32,33]$, to this author's knowledge, no study has been carried out to evaluate the influence of empathy on compassion, to test Vicente's idea [30] that empathetic feelings lead to the appearance of compassion. Finally, even though there is a burgeoning consensus that compassion is an emotion regulation strategy different from other emotion regulation strategies $[4,5,33,45]$, there is a lack of research that compares different emotion regulation techniques with compassion practice.

\section{Conclusions}

Research has shown that self-compassion is an important factor in mental health. On one hand, self-compassion is negatively related to mood disorders, such as anxiety and depression, and negative states, such as stress [14]. On the other hand, self-compassion is positively related to positive affect [17]. Moreover, research has provided evidence that compassion-based interventions may reduce anxiety, depression, stress [19], as well as, attenuate negative affect and augment positive affect [33].

Some authors [33] have suggested that compassion is an emotion regulation strategy different from other emotion regulation strategies, such as suppression or reappraisal. In accordance with this suggestion, it has been found that self-compassion and emotional regulation are positively related. Other authors [45] have gone further and have proposed emotion regulation as a possible mechanism of action for self-compassion on mental health.

Although research on compassion has shown that the compassion construct may be crucial for improving mental health, research on this topic is still emergent and more research is needed.

Acknowledgement: This work was supported by the Gobierno de Aragón [S48_17D] and the Fondo Europeo de Desarrollo Regional.

Conflict of Interests: The author declare no conflict of interest.

\section{Abbreviations}

MSC: Mindful Self-Compassion

\section{Bibliographic References}

1. Goetz JL, Keltner D, Simon-Thomas E. Compassion: An evolutionary analysis and empirical review. Psychol Bull. 2010; 136 3: 351-74.

2. The Dalai Lama. Essence of the Heart Sutra: The Dalai Lama's heart of wisdom teachings. Boston, MA: Wisdom Publications, 2005.

3. Bennett-Goleman T. Emotional alchemy: How the mind can heal the heart. New York: Three Rivers Press, 2001.

4. Brach T. Radical acceptance: Embracing your life with the heart of a Buddha. New York: Bantam Books, 2003.

5. Neff KD. The development and validation of a scale to measure self-compassion. Self and Identity. 2003; 2 3: 223-50.

6. Neff KD. Self-Compassion: An alternative conceptualization of a healthy attitude toward oneself. Self and Identity. 2003; 2 2: 85-101.

7. Buddhaghosa B. The path of purification. Sri Lanka, Kandy: Buddhist Publication Society, 1975.

8. Germer CK. El poder del mindfulness. Barcelona: Ediciones Paidós, 2017.

9. The Dalai Lama. An open heart: Practicing compassion in everyday life. Boston, MA: Little Brown and Company, 2001. 
10. Blatt SJ, Quinlan DM, Chevron ES, McDonald C, Zuroff D. Dependency and self-criticism: Psychological dimensions of depression. J Consult Clin Psychol. 1982; 50 1: 113-24.

11. Wood JV, Saltzberg JA, Neale JM, Stone AA, Rachmiel TB. Self-focused attention, coping responses, and distressed mood in everyday life. J Pers Soc Psychol. 1990; 58 6: 1027-36.

12. Nolenhoeksema S. Responses to depression and their effects on the duration of depressive episodes. J Abnorm Psychol. 1991; 100 4: 569-82.

13. Birnie K, Speca M, Carlson LE. Exploring self-compassion and empathy in the context of mindfulnessbased stress reduction (MBSR). Stress Health. 2010; 26 5: 359-71.

14. MacBeth A, Gumley A. Exploring compassion: A meta-analysis of the association between self-compassion and psychopathology. Clin Psychol Rev. 2012; 32 6: 545-52.

15. Van Dam NT, Sheppard SC, Forsyth JP, Earleywine M. Self-compassion is a better predictor than mindfulness of symptom severity and quality of life in mixed anxiety and depression. J Anxiety Disord. 2011; 25 1: 123-30.

16. Pauley G, McPherson S. The experience and meaning of compassion and self-compassion for individuals with depression or anxiety. Psychology and Psychotherapy-Theory Research and Practice. 2010; 83 2: 129 43.

17. Neff KD, Rude SS, Kirkpatrick KL. An examination of self-compassion in relation to positive psychological functioning and personality traits. Journal of Research in Personality. 2007; 41 4: 908-16.

18. Zessin U, Dickhaeuser O, Garbade S. The relationship between self-compassion and well-being: A metaanalysis. Applied Psychology-Health and Well being. 2015; 7 3: 340-64.

19. Neff KD, Germer CK. A pilot study and randomized controlled trial of the Mindful Self-Compassion Program. J Clin Psychol. 2013; 69 1: 28-44.

20. Bluth K, Gaylord SA, Campo RA, Mullarkey MC, Hobbs L. Making Friends with Yourself: A mixed methods pilot study of a Mindful Self-Compassion Program for adolescents. Mindfulness. 2016; 7 2: 479 92.

21. Sanso N, Galiana L, Cebolla A, Oliver A, Benito E, Ekman E. Cultivating emotional balance in professional caregivers: A pilot intervention. Mindfulness. 2017; 8 5: 1319-27.

22. Jazaieri H, McGonigal K, Jinpa T, Doty JR, Gross JJ, Goldin PR. A randomized controlled trial of compassion cultivation training: Effects on mindfulness, affect, and emotion regulation. Motiv Emotion. 2014; 38 1: 2335.

23. Halifax J. The precious necessity of compassion. J Pain Symptom Manage. 2011; 41 1: 146-53.

24. Gilbert P. Compassion focused therapy: Distinctive features London: Routledge, 2010.

25. García-Campayo J, Navarro-Gil M, Demarzo M. Attachment-based compassion therapy. Mindfulness and Compassion, 2016; 1 2: 68-74.

26. Bornemann B, Singer T. A cognitive neuroscience perspective-The ReSource model. In Singer T, Bolz M. Eds. Compassion: Bridging practice and science. 2013. p. 178-191.

27. Reddy SD, Negi LT, Dodson-Lavelle B, Ozawa-de Silva B, Pace TWW, Cole SP, et al. Cognitive-Based Compassion Training: A promising prevention strategy for at-risk adolescents. J Child Fam Stud. 2013; 22 2: 219-30.

28. Neff KD, Pommier E. The relationship between self-compassion and other-focused concern among college undergraduates, community adults, and practicing meditators. Self and Identity. 2013; 12 2: 160-76.

29. Keltner D, Goetz JL. Compassion. In Baumeister RF, Vohs KD, Eds.. Encyclopedia of social psychology. Thousand Oaks (CA): Sage Publications. 2007. p. 159-161.

30. Simón V, Germer CK, Bayés, R. La compasión: el corazón del mindfulness. Barcelona: Sello Editorial, 2015.

31. Lutz A, Brefczynski-Lewis J, Johnstone T, Davidson RJ. Regulation of the neural circuitry of emotion by compassion meditation: Effects of meditative expertise. Plos One. 2008; 3 3: e1897.

32. Klimecki OM, Leiberg S, Lamm C, Singer T. Functional neural plasticity and associated changes in positive affect after compassion training. Cerebral Cortex. 2013; 23 7:1552-61.

33. Klimecki OM, Leiberg S, Ricard M, Singer T. Differential pattern of functional brain plasticity after compassion and empathy training. Social Cognitive and Affective Neuroscience. 2014; 9 6: 873-9.

34. Leiberg S, Klimecki O, Singer T. Short-term compassion training increases prosocial behavior in a newly developed prosocial game. Plos One. 2011; 6 3: e17798.

35. Batson CD, Oquin K, Fultz J, Vanderplas M, Isen AM. Influence of self-reported distress and empathy on egoistic versus altruistic motivation to help. J Pers Soc Psychol. 1983; 45 3: 706-18. 
36. Eisenberg N, Fabes RA, Miller PA, Fultz J, Shell R, Mathy RM, et al. Relation of sympathy and personal distress to pro-social behavior: A multimethod study. J Pers Soc Psychol. 1989; 57 1: 55-66.

37. Figley CR. Compassion stress: Toward its measurement and management. Family Therapy News, 1993; 24 1, 3-16.

38. Klimecki O, Ricard M, Singer T. Empathy versus compassion: lessons from 1st and 3rd person methods. In Singer T, Bolz M. Eds. Compassion: Bridging practice and science. 2013. p. 272-287.

39. Danucalov MAD, Kozasa EH, Ribas KT, Galduroz JCF, Garcia MC, Verreschi ITN, et al. A yoga and compassion meditation program reduces stress in familial caregivers of Alzheimer's disease patients. Evidence-Based Complementary and Alternative Medicine. 2013; 513149.

40. Barsade SG, O'Neill OA. What's Love got to do with it? A longitudinal study of the culture of compassionate love and employee and client outcomes in a long-term care setting. Adm Sci Q. 2014; 59 4: 551-98.

41. Gross JJ. Emotion regulation: Affective, cognitive, and social consequences. Psychophysiology. 2002; 39 3: 281-91.

42. Thompson RA. Emotion regulation: a theme in search of definition. Monogr Soc Res Child Dev. 1994; 59 23: 25-52.

43. Aldao A, Nolen-Hoeksema S, Schweizer S. Emotion-regulation strategies across psychopathology: A metaanalytic review. Clin Psychol Rev. 2010; 30 2: 217-37.

44. Gross JJ, Muñoz RF. Emotion regulation and mental health. Clinical Psychology: Science and Practice. 1995; 2: 151-64.

45. Finlay-Jones AL, Rees CS, Kane RT. Self-compassion, emotion regulation and stress among australian psychologists: Testing an emotion regulation model of self-compassion using structural equation modeling. Plos One. 2015; 10 7: e0133481.

46. Gross JJ. Emotion regulation: Affective, cognitive, and social consequences. Psychophysiology. 2002; 39 3: 281-291.

(C) 2019 por los autores; Esta obra está sujeta a la licencia de Reconocimiento 4.0 Internacional de Creative Commons. Para ver una copia de esta licencia, visite http://creativecommons.org/licenses/by-nc-nd/4.0/. 